\title{
Syphilis in Poland is on the rise and underreported
}

\author{
Zbigniew Teter ${ }^{1}$, Gabriela Majkut ${ }^{2}$, Waldemar Wierzba ${ }^{3}$, Andrzej Śliwczyński ${ }^{4}$, Melania Brzozowska $^{4}$, Andrzej Jacyna ${ }^{2}$, \\ Michał Marczak ${ }^{4}$, Michał Myśliwiec ${ }^{5}$
}

${ }^{1}$ Dermatology Clinic, Military Institute of Medicine, Warsaw, Poland

${ }^{2}$ National Health Fund, Warsaw, Poland

${ }^{3}$ Satellite Campus in Warsaw, University of Humanities and Economics in Lodz, Poland

${ }^{4}$ Division of Quality Services, Procedures and Medical Standards, Medical University of Lodz, Lodz, Poland

${ }^{5}$ Lomza State University of Applied Sciences and Department of Nephrology and Transplantation, Medical University of Bialystok, Bialystok, Poland

Adv Dermatol Allergol 2019; XXXVI (2): 192-195

DOI: https://doi.org/10.5114/ada.2019.84595

\begin{abstract}
Introduction: Despite the availability of diagnostic tests and effective treatment, there has been a problem with vigilance and reporting of that infectious disease in many countries including Poland.

Aim: To compare the incidence of syphilis in Poland in years 2010-2016 according to the mandatory epidemiological surveillance system with the data of the National Health Fund (NHF).

Material and methods: Data of the NHF in Poland were collected. The total number of patients with syphilis (all forms) was estimated on the basis of their unique identifying numbers (PESEL).

Results: The steady increase in the incidence of syphilis in Poland throughout 2010-2016 was found, apart from the congenital form of the disease, which decreased since 2010. The higher prevalence of syphilis was noted in men. The number of hospitalized patients remained constant. According to the data of the NHF, the number of cases of syphilis in Poland was twofold higher as compared to the statistics of the mandatory epidemiological surveillance system (National Institute of Public Health - National Institute of Hygiene, NIPH-NIH), which was the basis of reports published up to date.

Conclusions: Our work shows that there is a remarkable underreporting of syphilis in the mandatory epidemiological surveillance system in Poland, involving also hospitalized patients. The use of the data of NHF in the surveillance of syphilis in Poland is proposed.
\end{abstract}

Key words: syphilis, epidemiology, Poland, reporting.

\section{Introduction}

Syphilis is a mainly sexually transmitted infection and remains a serious health problem particularly in pregnant women who may transmit the disease vertically to the foetus. Untreated syphilis may result in death and serious disability. Despite the availability of diagnostic tests and effective treatment, there has been a problem with vigilance and reporting of that infectious disease in many countries including Poland.

Although in Poland there has been an obligatory system of reporting infectious diseases (including syphilis), it remains incomplete for several reasons. Individual notifications of syphilis are to be submitted to the SanitaryEpidemiological Stations by physicians and laboratory workers. The Provincial Sanitary-Epidemiological Stations send the aggregated data to the National Institute of
Public Health - National Institute of Hygiene (NIPH-NIH). $\mathrm{NIPH}-\mathrm{NIH}$ publishes the collected data in annual bulletins "Infectious diseases and poisonings in Poland". Despite the detailed regulations, overworked physicians and laboratory workers may ignore them, as filling in a special obligatory form takes some minutes of their precious time. Additionally, because of the intimacy of syphilis, full patient identification data may not be provided, particularly from private practices. These are the main causes of underreporting of syphilis cases in the epidemiological surveillance system.

Another system of syphilis reporting in Poland comes from the National Health Fund, which is the only public payer in the country, so its data are more complete. Unfortunately, so far it has not been utilized for the sanitary and epidemiological purposes.

Address for correspondence: Gabriela Majkut MD, PhD, National Health Fund, 2 Hankiewicza St, 02-103 Warsaw, Poland, phone: + 482257264 05, e-mail: gabriela.majkut@nfz.gov.pl

Received: 6.11.2017, accepted: 15.01.2018. 
Aim

The aim of the present work was to compare the incidence of syphilis in Poland in years 2010-2016 according to the mandatory epidemiological surveillance system with the data of the National Health Fund. Additionally, the number of patients with syphilis per 100000 population in particular regions in Poland was provided.

\section{Material and methods}

The following analysis was based on data derived from the routine mandatory epidemiological surveillance system, sent to the National Institute of Public Health - National Institute of Hygiene (NIPH-NIH) by SanitaryEpidemiological Stations, and published in the annual bulletins "Infectious diseases and poisonings in Poland" 2010-2016.

Data of the National Health Fund in Poland were collected by means of the SAP Business Objects system. For each patient (ambulatory or discharged from hospital) in
Poland, the diagnoses have been consistent with the International Classification of Diseases (ICD-10) taxonomy and encoded as A50, A51, A52, and A53.

The total number of patients with syphilis (all forms) was estimated on the basis of their unique identifying numbers (PESEL). Thus for each year, the unique PESEL number was counted only once, regardless of the form of the treatment (inpatient or outpatient) or the total (summary) number of the visits.

\section{Results}

Table 1 shows the total number of patients with syphilis in years 2010-2016 according to the data of NIPH-NIH (mandatory epidemiological surveillance system) and NHF (payer). There is a continuous growth of patients with syphilis from 2010 to 2016 in both systems, although the NHF data are about twice higher than NIPH-NIH.

As Table 2 shows, according to the NHF reporting system, between 2010 to 2016, an increase in the rate of syphilis per 100000 population was observed in all

Table 1. The total number of patients with syphilis (all forms) in 2010-2016 according to the data of NIPH-NIH as compared to NHF, with the rate of syphilis among men (NHF)

\begin{tabular}{|c|c|c|c|c|c|c|c|c|}
\hline \multirow[t]{2}{*}{ Parameter } & & \multicolumn{7}{|c|}{ The number of patients with syphilis (A51. A52. A53) in 2010-2016 } \\
\hline & & 2010 & 2011 & 2012 & 2013 & 2014 & 2015 & 2016 \\
\hline \multirow[t]{2}{*}{ Source of data } & $\mathrm{NIPH}-\mathrm{NIH}$ & 914 & 941 & 961 & 1258 & 1213 & 1338 & 1596 \\
\hline & NHF & 2437 & 2641 & 3028 & 3408 & 3412 & 3969 & 4052 \\
\hline \multicolumn{2}{|c|}{ Percentage of men (source: NHF) } & 71 & 72.4 & 72.2 & 73.3 & 75.2 & 77.2 & 77.4 \\
\hline
\end{tabular}

Table 2. Syphilis cases per 100000 population in Poland by province (voivodeship) in 2010-2016

\begin{tabular}{|c|c|c|c|c|c|c|c|}
\hline Provincial Branch of National Health Fund & 2010 & 2011 & 2012 & 2013 & 2014 & 2015 & 2016 \\
\hline 01 - Dolnośląski & 4.0 & 4.4 & 5.1 & 5.6 & 5.5 & 6.2 & 7.7 \\
\hline 02 - Kujawsko-Pomorski & 7.6 & 7.1 & 5.9 & 6.1 & 7.2 & 8.7 & 8.5 \\
\hline 03 - Lubelski & 2.4 & 2.8 & 1.5 & 3.1 & 2.6 & 3.8 & 5.8 \\
\hline $04-$ Lubuski & 1.1 & 2.6 & 2.2 & 2.8 & 4.5 & 5.4 & 3.6 \\
\hline 05 - Łódzki & 8.8 & 11.6 & 17.4 & 24.1 & 20.7 & 17.3 & 16.0 \\
\hline 06 - Małopolski & 8.7 & 8.8 & 10.3 & 11.2 & 10.1 & 10.5 & 9.7 \\
\hline 07 - Mazowiecki & 12.6 & 13.2 & 16.5 & 16.6 & 17.5 & 23.2 & 22.5 \\
\hline 08 - Opolski & 4.0 & 2.4 & 1.8 & 4.8 & 6.0 & 2.6 & 5.3 \\
\hline 09 - Podkarpacki & 1.0 & 1.8 & 1.3 & 2.3 & 2.2 & 2.7 & 2.4 \\
\hline 10 - Podlaski & 4.7 & 3.5 & 6.2 & 5.8 & 6.4 & 7.0 & 5.8 \\
\hline 11 - Pomorski & 3.4 & 3.1 & 4.0 & 4.9 & 8.5 & 10.8 & 12.7 \\
\hline 12 - Śląski & 5.3 & 6.1 & 6.3 & 5.8 & 5.4 & 6.3 & 6.0 \\
\hline 13 - Świętokrzyski & 3.8 & 1.7 & 2.6 & 2.7 & 2.7 & 2.9 & 6.4 \\
\hline 14 - Warmińsko-Mazurski & 1.7 & 2.4 & 3.2 & 4.0 & 5.1 & 7.6 & 9.7 \\
\hline 15 - Wielkopolski & 7.9 & 9.0 & 9.6 & 10.7 & 8.4 & 13.0 & 13.0 \\
\hline 16 - Zachodniopomorski & 8.9 & 11.0 & 7.3 & 8.6 & 10.8 & 8.3 & 8.5 \\
\hline
\end{tabular}


Table 3. The number of cases of congenital syphilis in 2010-2016 according to the data of NIPH-NIH as compared to NHF

\begin{tabular}{lccccccc}
\hline Source of data & \multicolumn{7}{c}{ The number of cases of congenital syphilis (A50) in 2010-2016 } \\
\cline { 2 - 9 } & 2010 & 2011 & 2012 & 2013 & 2014 & 2015 & 2016 \\
\hline NIPH-NIH & 18 & 14 & 32 & 18 & 20 & 12 & 16 \\
\hline NHF & 88 & 75 & 45 & 40 & 50 & 42 & 42 \\
\hline
\end{tabular}

Table 4. The number of hospitalized patients with syphilis (all forms) in 2013-2016 according to the data of NIPH-NIH as compared to $\mathrm{NH}$

\begin{tabular}{lcccc}
\hline \multirow{2}{*}{$\begin{array}{l}\text { Source } \\
\text { of data }\end{array}$} & \multicolumn{4}{c}{$\begin{array}{c}\text { The number of hospitalized patients with } \\
\text { syphilis (all forms) in }\end{array}$} \\
\cline { 2 - 5 } & 2013 & 2014 & 2015 & 2016 \\
\hline NIPH-NIH & 288 & 244 & 258 & 290 \\
\hline NHF & 602 & 595 & 581 & 620 \\
\hline
\end{tabular}

the voivodeships apart from Zachodniopomorski where it remained at the same level. The highest rate of syphilis in 2016 (over 10) according to NHF was observed in Mazowiecki, Łódzki, Wielkopolski and Pomorski regions. The lowest rate of syphilis was reported in Podkarpacki, Lubuski, Opolski, Podlaski and Lubelski regions. The highest increase, more than doubled, as compared to 2010 was found in Warmińsko-Mazurski, Pomorski, Podkarpacki, and Lubelski regions.

Table 3 shows that the number of patients with congenital syphilis markedly decreased since 2010 according to both reporting systems (by half, according to NHF).

Table 4 shows that the number of hospitalized patients with all forms of syphilis according to NHF was almost twice as high as reported in the epidemiological surveillance system but remained almost constant throughout 2013-2016 according to both reporting systems.

\section{Discussion}

The steady increase in the incidence of syphilis in Poland throughout 2010-2016 was observed, apart from a congenital form of the disease, which decreased since 2010. The rate of syphilis among men was three times higher than that of women (despite the fact that woman's anatomy makes her more vulnerable to the disease). The number of hospitalized patients remained constant. According to the data of the National Health Fund, the number of cases of syphilis in Poland was twofold higher as compared to the data of the mandatory epidemiological surveillance system, which was the basis of reports published up to date [1]. Our analysis shows that there is a remarkable underreporting of syphilis in the epidemiological surveillance system in Poland, involving also hospitalized patients. Our study suggests the use of the data of NHF also in the surveillance system. Data of NHF are easily available and already digitalized, whereas the papers reported to NIPH-NIH need digitalization. Moreover, the NHF data appear very quickly, up to the $10^{\text {th }}$ day of the following month, so that they can be used for the prompt and quick surveillance of the epidemiological situation not only of syphilis but also every infectious disease in the country.

The strength of our study is the completeness of the NHF data, which is the only public payer in Poland for all medical procedures and drug reimbursement. However, due to the clinical course of this disease, some infected people may still be undiagnosed.

A weakness of the paper is presenting collected data for primary infectious syphilis and secondary one as well as early latent syphilis. We were also not able to discern between incidence and prevalence of syphilis, as both were reported together. Notwithstanding, the prevalence of new cases is obvious, as primary infectious syphilis is cured in most of the cases.

It should also be noted that even though the National Health Fund remains the only public payer in Poland, an unknown number of patients use private medical services, and therefore the total number of patients with syphilis in Poland may be even greater.

Our present data are in line with the previous study which showed that only every second doctor examined knew the regulations on the obligatory reporting of infectious diseases to the epidemiological surveillance system. Hence only half of them filled in proper information forms [2]. Low awareness of doctors and their overworking result in marked underreporting of syphilis and other infectious diseases in Poland. Filling in an appropriate form takes some minutes of their precious time, so their willingness to fill in an additional questionnaire has been low. Similar underreporting most probably applies to laboratory workers.

Underreporting of syphilis is a problem not only in Poland. In Ireland, the return of acute infectious syphilis enhanced forms was around 60\% in 2013 and 2015 as compared with $73 \%$ in 2014 [3].

Our data suggest a new possibility of improvement of the surveillance system for syphilis and other infectious diseases in Poland, by means of broader utilization of the data of NHF, which so far are used only for financial purposes. It contains several pieces of valuable information including sex, age, and place of residence. Our suggestion is consistent with the strategy of the European Center for Disease Prevention and Control, released in 2013 
for 2014-2020, which advocates binding of existing databases for the epidemiological surveillance systems [4]. A great advantage may be a low cost and possibility of picking up important additional information which may be of potential value for the epidemiological surveillance systems in the European Union. A potential setback may be legal problems related to the protection of personal data of the patients.

Increased incidence of syphilis in Poland is consistent with that of other European countries, although there are problems with reporting. According to Uusküla et al. and Herbert and Middleton, the highest incidence was reported in Belarus in 1996 with an incidence rate of 209.7 cases per 100000 person-years, compared to between 2 and 6 cases per 100000 in 2004 in Hungary and the Czech Republic [5, 6]. Similar assumptions could be assigned to the estimated incidence in the Ukraine. The incidence rate of syphilis within the Russian Federation was > 50 cases per 100000 person-years in 2005 [5].

In 2014, among 29 EU/EEA Member States, 24541 syphilis cases were reported (no data were available for Austria and Lichtenstein), an overall rate of 5.1 per 100000 population. Reported syphilis rates were six times higher in men than in women. Trends since 2010 show that overall syphilis rates have been increasing, particularly among men, mainly due to increased cases of men having sex with men (MSM population). The highest rate was observed in Malta (11.5 per 100000 population) followed by Lithuania (8.7), Iceland (7.7) and Spain (7.7). Rates below 2.5 per 100000 population were observed in Croatia, Cyprus, Greece, Italy, and Slovenia. Between 2010 and 2014, many countries, particularly in Western Europe, show a sharp increase in the number of reported syphilis infections, with increases of over $50 \%$ in Belgium, France, Germany, Iceland, Ireland, Luxembourg, Malta, Norway, Portugal and the United Kingdom [7].

Jakopanec et al. reported that in Norway most patients with syphilis belong to MSM population, but of 152 heterosexually infected men, $73 \%$ were infected abroad, and among 56 women, 40\% were infected abroad [8].

Generally, in Europe, diverging trends can be observed between genders, with a marked increase among men and a decrease among women (male-to-female ratio in 2014 was $6.2: 1$ ), which makes MSM the most prominent behavioural risk factor. In 2014, the largest proportion of cases was reported in the age group above 45 years of age (30\%). However, almost equally large proportions of cases were reported in the 25-34 years (29\%) and $35-44$ years (27\%) groups [4].

For comparison, in Brazil syphilis was associated with an age of 25-34 years, little education, and single marital status. The main associated behavioural factors were: men who have sex with men, drug users and co-infected with HIV and other sexually transmitted diseases. The use of alcohol, marijuana, cocaine, and crack was significantly associated with syphilis [9].
The growing number of patients with syphilis shows that the problem is not solved and that better and early reporting may play a crucial role in preventive measures and appropriate treatment.

\section{Conclusions}

The growing number of patients with syphilis in Poland suggests that additional measures must be introduced in our country to surveillance syphilis, as the present epidemiological surveillance system of reporting syphilis cases is inefficient. We suggest utilizing data from the National Health Fund also for the purpose of the disease epidemiological surveillance.

\section{Conflict of interest}

The authors declare no conflict of interest.

\section{References}

1. Majewski S, Rudnicka I. Sexually transmitted diseases in Poland in 2011. Przegl Epidemiol 2013; 67: 283-6.

2. Godala M, Szatko F. Notifiability of infectious diseases. Probl Hig Epidemiol 2010; 91: 198-213.

3. HSE. Health Protection Surveillance Centre. Syphilis in Ireland, 2015, Dublin: Health Protection Surveillance Centre; 2016.

4. European Centre for Disease Prevention and Control. Longterm surveillance strategy 2014-2020. Stockholm: ECDC; 2013.

5. Uusküla A, Puur A, Toompere K, DeHovitz J. Trends in the epidemiology of bacterial sexually transmitted infections in Eastern Europe, 1995-2005. Sex Transm Infect 2010; 86: 6-14.

6 . Herbert LJ, Middleton SI. An estimate of syphilis incidence in Eastern Europe. J Glob Health 2012; 2: 010402.

7. European Centre for Disease Prevention and Control. Annual Epidemiological Report 2016 - Syphilis. Stockholm: ECDC 2016.

8. Jakopanec I, Grjibovski AM, Nilsen O, Aavitsland P. Syphilis epidemiology in Norway, 1992-2008: resurgence among men who have sex with men. BMC Infect Dis 2010; 10: 105.

9. Gomes NC, Meier DA, Pieri FM, et al. Prevalence and factors associated with syphilis in a Reference Center. Rev Soc Bras Med Trop 2017; 50: 27-34. 